\title{
Perspective for change: establishing the need for clinical instructor competencies in physical therapist education
}

\author{
Catherine Bilyeu'* Amanda Sharp² and Katherine Myers $^{3}$ \\ 'Assistant Professor, Clinical Education Team, University of Colorado, Aurora, CO, USA; ${ }^{2}$ Assistant Professor and Director of Clinical Education, \\ University of Minnesota, Minneapolis, MN, USA; ${ }^{3}$ Assistant Professor and Director of Clinical Education, Duke University, Durham, NC, USA
}

\section{Abstract}

Current issue: Clinical instructors (CIs) are instrumental in the development of competent, entry-level physical therapist graduates. Despite this key role, CIs are often deficient in formal knowledge of the learning sciences that influence quality of clinical education experiences. Clinical education stakeholders also lack a standardized and consistent approach to defining and assessing clinical teaching skills, resulting in an inability to provide adequate feedback and growth opportunities for CIs.

Perspective: A gap exists between qualitative descriptions of clinical teaching behaviors and the ability to objectively assess those behaviors in CIs. Grounded in the Model of Excellence in Physical Therapist Education, this perspective calls attention to and proposes steps toward excellence in clinical education. Defining essential competencies of clinical teaching in the physical therapy profession requires a systematic approach. The competencies established through this approach then become the foundation for creating a meaningful assessment tool of CI performance.

Implications for clinical education: Developing educator competencies and a related assessment tool for CIs allows for the provision of meaningful feedback, the creation of targeted professional development programs, and opportunities for recognition of clinical teaching excellence. Without effective CIs, new graduates may be inadequately equipped to contribute to the profession's vision of educational excellence.

Keywords: clinical education; competency; assessment

MESH terms: education; professional competence; performance appraisal

$\mathrm{D}$ octor of Physical Therapy (DPT) program graduates enter an increasingly complex work environment, demanding a high level of skill and adaptability in clinical practice. ${ }^{1}$ It is essential that the academic and clinical components of education transform students into adaptive learners who can manage these complexities. Adaptive learning focuses not only on skill or knowledge, but also on innovative problem solving and clinical reasoning. This creates a foundation for new graduates to develop into adaptive experts who can comprehensively meet the needs of patients. For students, adaptive learning develops with the guidance of clinical instructors (CIs) during the critical experiential learning that occurs in the clinic. These clinical education experiences account for up to $33 \%$ of DPT students' educational hours. ${ }^{2} \mathrm{CIs}$ are the primary educators responsible for fostering learning during that time, and immensely influence the development and professional formation of DPT students. ${ }^{3-5}$ It is therefore critical for these individuals to have strong skills and a foundation of educational knowledge as clinical educators.

The National Study of Excellence and Innovation in Physical Therapist Education explored the concept of excellence in education, resulting in a conceptual model 
that represents key elements of educational excellence. ${ }^{6}$ Educational excellence relies, in part, on competent educators and the study's authors emphasized that excellence is required at both academic and clinical levels of education for the profession to meet the needs of society. ${ }^{1}$ Findings suggested, however, that many individuals within DPT faculty, including CIs, have gaps in knowledge related to learning sciences. Learning science encompasses broad educational concepts focused on enhancing student learning such as theories of learning, situated learning, adaptive expertise, pedagogy, cognitive psychology, and instructional design. ${ }^{7}$ Competent CIs who possess enhanced knowledge of learning sciences will be better able to guide students through essential clinical education experiences. Gaps in these knowledge areas can impact student learning and ultimately the vision of educational excellence within the profession.

CIs function in dual roles as educators and healthcare providers within complex healthcare environments. While the focus here is on CIs as educators, it is important to recognize that most CIs identify as clinician first and educator second. ${ }^{8,9}$ As such, CIs typically pursue readily available continuing education paths related to clinical practice expertise. Similarly, these individuals participate in performance reviews focused primarily on healthcare delivery performance. Conversely, when it comes to their role as educators, CIs have fewer opportunities to develop teaching skills, nor do they see as much value in continuing education related to teaching skills, with only $31.2 \%$ of CI's relying on the American Physical Therapy Association (APTA) Credentialed Clinical Instructor Program (CCIP) as their source of training. ${ }^{8,9}$ The CCIP is an excellent starting place for providing a teaching foundation for CIs, but evidence is mixed on the efficacy of this program. ${ }^{8,10-13}$ According to Buccieri et al., ${ }^{10}$ this program is 'is not the definitive pathway to expertise for the clinical instructor' (p. 18). Recently, booster modules have been added to the CCIP and are available for purchase through the APTA Learning Center. ${ }^{14}$ These cover narrow content areas but may support necessary skills related to feedback provision and using objectives to enhance teaching. Factors that may be missing from this approach to CI development include relevant content linked to established core competencies, opportunities for practice, longitudinal program design, ongoing opportunities for feedback and reflection, intentional community building, and institutional support. ${ }^{15}$ The lack of such educational opportunities contributes to a knowledge gap in foundational learning science principles, and therefore, CIs struggle to apply those concepts in a clinical setting.

Ongoing development of a Cl's skill as an educator is also hindered by lack of meaningful assessment. ${ }^{3}$ There is little evidence that CIs routinely receive consistent feedback on clinical teaching skills. ${ }^{1,9}$ No standardized framework exists to outline competence expectations or provide guidance to stakeholders evaluating CI performance, making objective assessment challenging. Objective assessment is necessary to identify strengths and gaps in CI teaching competence, to guide feedback, and to provide relevant opportunities for growth. ${ }^{3,16}$ An effective assessment mechanism should be based on defined competencies and contemporary standards of educational excellence that are expected of all CIs. The following perspective will further articulate the need to establish nationally recognized teaching competencies for physical therapist CIs and outline subsequent steps required to fill the identified gap in teaching preparedness.

\section{Perspective}

Excellence in clinical education is attainable if a standardized pathway is established for CIs to develop as effective clinical educators, allowing them to refine skills through assessment and feedback as they aspire to teaching expertise. Establishing minimum competency standards related to contemporary evidence-based education principles is the first step in this process. Without established clinical teaching competencies, there are no clear standards to which CIs can aspire, no valid mechanisms by which to assess them, and no direction for professional development opportunities.

\section{Current status: defining and assessing excellence in clinical teaching}

Extensive qualitative evidence exists describing factors that contribute to quality DPT clinical education experiences. ${ }^{3-5,8,16-19}$ This literature highlights the central importance of the $\mathrm{CI}$ in creating a quality clinical education experience and identifies broad categories of critical CI capabilities that include interpersonal, teaching, and evaluation skills., ${ }^{3,4,8,16,17}$ Within these categories, evidence demonstrates the importance of CI characteristics such as confidence, adaptability in teaching style, ability to facilitate clinical reasoning and critical reflection, and competence in providing effective formative and summative feedback. ${ }^{3,4,8,16,17}$ Existing literature also describes the pathways or processes CIs follow to gain proficiency as a clinical teacher. ${ }^{3,8,17,20}$ The term 'expert' is frequently used to describe these proficient CIs; however, the definitions of expertise in these studies are subjective as they rely solely on student and peer perspectives. Many attributes of successful CIs are described in this body of literature, yet these characteristics are not succinctly defined, making them difficult to assess objectively. $3,4,8,16,17$

Several assessment tools exist within the physical therapy profession for the purpose of evaluating CI performance, but they are not widely disseminated or utilized. 
Table 1. Benefits and challenges of current physical therapist clinical instructor assessment tools

\begin{tabular}{|c|c|c|}
\hline Assessment tool & Benefits & Challenges \\
\hline APTA PTSE ${ }^{16}$ & $\begin{array}{l}\text { - Content validity established in development } \\
\text { process } \\
\text { - Completed by student (external viewpoint) } \\
\text { - Completed by student at two time points in } \\
\text { an experience (midterm and final evaluation) }\end{array}$ & $\begin{array}{l}\text { - Tool design makes assumptions about candid feedback, } \\
\text { yet threats to internal validity (reliability) identified } \\
\text { due to lack of student willingness to share honest } \\
\text { feedback } \\
\text { - Poor discriminative ability'2 } \\
\text { - Not valuable as stand-alone tool to assess Cl } \\
\text { effectiveness }{ }^{12} \\
\text { - Single perspective (student) } \\
\text { - Not linked to contemporary definition of excellence } \\
\text { in teaching } \\
\text { - Last updated in } 2003\end{array}$ \\
\hline $\begin{array}{l}\text { APTA Guidelines and Self } \\
\text { Assessments for Clinical Education }{ }^{21}\end{array}$ & $\begin{array}{l}\text { - Comprehensive: includes self-assessments } \\
\text { for Cls, SCCEs, and clinical sites }\end{array}$ & $\begin{array}{l}\text { - Length of tool could impact frequency of use } \\
\text { - Unclear how widely tool is utilized } \\
\text { - No published psychometric properties } \\
\text { - Single perspective (self) } \\
\text { - Not linked to contemporary definition of excellence } \\
\text { in teaching } \\
\text { - Last updated in } 2004\end{array}$ \\
\hline $\mathrm{CTEQ}^{17}$ & $\begin{array}{l}\text { - Valid and reliable instrument to measure } \mathrm{Cl} \\
\text { self-perception of clinical teaching. } \\
\text { - Self-assessment in four areas: learning } \\
\text { experience, learning environment, } \\
\text { communication, and evaluation } \\
\text { - Developed in } 2017\end{array}$ & $\begin{array}{l}\text { - Single perspective } \\
\text { - Not linked to contemporary definition of excellence } \\
\text { in teaching }\end{array}$ \\
\hline
\end{tabular}

Table 1 summarizes the benefits and challenges of the three most recognized published tools. Despite their intrinsic benefits, all tools have drawbacks such as reliance on a single perspective and a lack of specificity to contemporary teaching strategies. ${ }^{21-23}$ Additionally, no data exist detailing how frequently these tools are utilized, which makes it difficult to determine how consistently CIs are assessed or provided with feedback. The tool most referenced in clinical settings is the APTA Physical Therapist Student Evaluation: Clinical Experience and Clinical Instruction (PTSE). ${ }^{22}$ The PTSE is an eight-page document developed in 2003 as a mechanism for students to assess CIs, but unfortunately, lacks robust psychometric properties. ${ }^{12,24}$ Students are expected to share the completed evaluation with their CI; however, it is unclear how consistently or honestly students share their feedback directly with their CIs. ${ }^{3,12}$ The APTA's Guidelines and Self Assessments for Clinical Education ${ }^{21}$ is a comprehensive guide for clinical sites, site coordinators, and CIs. Last updated in 2004, the self-assessment section for CIs is 14 pages long, includes 82 individual questions, and has six free response sections for extended comments and plans. In today's demanding healthcare environment, it is unrealistic to expect CIs to regularly complete such a cumbersome and potentially outdated document.

The most contemporary tool is the Clinical Teaching Effectiveness Questionnaire (CTEQ). ${ }^{23}$ Developed by
Wormley et al., ${ }^{23}$ the CTEQ is a validated self-reflection tool for CIs. Self-reflection is an important mechanism in the development of skill and expertise, but there can be concerns related to the accuracy of rating in such tools; high achievers tend to underrate performance and low achievers tend to overrate performance. ${ }^{25}$ When either of these rating errors occur, it can influence how CIs view the need for improvement or initiate a plan for growth. Self-assessment therefore should be enhanced by an external validation process, such as gathering input from students, peers, and faculty (multisource assessment). Galbraith et al. ${ }^{25}$ also suggest that results from a self-assessment could be norm-referenced if formal clinical teaching competencies existed. This would allow users of the tool a more objective comparison of where their teaching behaviors lie related to expected competencies.

\section{Why start with core competencies?}

Competence is defined as 'a set of behaviors that describe excellent performance in a particular work context'. ${ }^{26(p .109)}$ Competencies are developed via various consensus-based decision-making processes such as a Delphi process, nominal group technique, or consensus development conferences, thus allowing for objective definitions of performance expectations within a profession. ${ }^{26-29}$ Each profession needs to identify competencies within its own scope of work and responsibility, and cannot rely on 
those identified in other professions. The broad qualitative literature base that exists specific to physical therapist clinical education provides a strong foundation of language around clinical teaching excellence, from which we can work to establish clearly defined clinical educator competencies. ${ }^{3,4,8,10,11}$ Defined competencies then provide the foundation for the creation of an assessment tool and targeted professional development activities. Clearly defined performance expectations also allow educators to compare their teaching approaches with evidence-based standards and more easily identify gaps in knowledge and skill. ${ }^{30,31}$

Literature in other health professions advocates for the process of first identifying and defining core teaching competencies..$^{28,32}$ Medicine ${ }^{29,33}$ and nursing ${ }^{28,34}$ used established clinician core competencies as a platform to create clinical educator competencies. In both professions, this led to the formation of widely utilized teaching assessment tools. In examining the methodology used to create these tools, it is evident that they are based on models of competence and constructed with learning science and pedagogical theory in mind. ${ }^{28,29,33,34}$ Linking an assessment tool to core competencies allows for the assessment of CI skills, knowledge, and attitudes associated with exemplary teaching, and reinforces the importance of advanced skill acquisition through self-reflection, peer feedback, and training programs throughout an individual's career. ${ }^{35}$

\section{Implications for clinical education}

The lack of established CI teaching competencies and the lack of standardized assessment of such competencies contribute to the gap in CI preparedness to teach. ${ }^{3,16,29}$ Quality clinical education is multifaceted, but its foundation lies in $\mathrm{CI}$ teaching competence. ${ }^{3-5,16,18}$ We suggest that there is a critical need to undertake a sequential process to ensure competence in teaching through the following steps: (1) come to consensus as a profession on clinical teaching competencies, (2) develop and validate a multisource tool that could be used uniformly across the profession to assess CI competence, and (3) use the data and individual outcomes from the assessment tool to recognize excellence in clinical instruction and drive the creation of professional development opportunities to fill gaps in the performance (Fig. 1).

As a profession, we are well staged to embark on a consensus process to establish core educator competencies, building from the extensive literature documenting CI attributes in physical therapy, ${ }^{3,4,8,17}$ the Model of Excellence in Physical Therapist Education, ${ }^{6,16}$ the related work in other healthcare disciplines, ${ }^{28,33}$ and the momentum on using competencies in our profession created by the Education Leadership Partnership. ${ }^{36}$ We propose the competencies be grounded in established theories of skill acquisition $^{37,38}$ and based on the Model of Excellence in Physical Therapist Education. ${ }^{6}$ Using a structured means of competency development, such as a Delphi process involving experts from the field, provides a national platform for both discovery and dissemination of competencies, hopefully facilitating widespread acceptance and application of uniform clinical teaching standards.

A nationally adopted set of competencies would be the foundation from which to build a multisource assessment tool for CIs. Assessment tools developed from competencies allow for performance evaluation that is consistent and equitable for all CIs. ${ }^{26}$ Such assessment could also facilitate the identification of gaps in skills, the creation of individualized growth opportunities, and opportunities for recognition of clinical teaching excellence. By highlighting how gaps in understanding of the learning sciences impact the vision and path to excellence as a

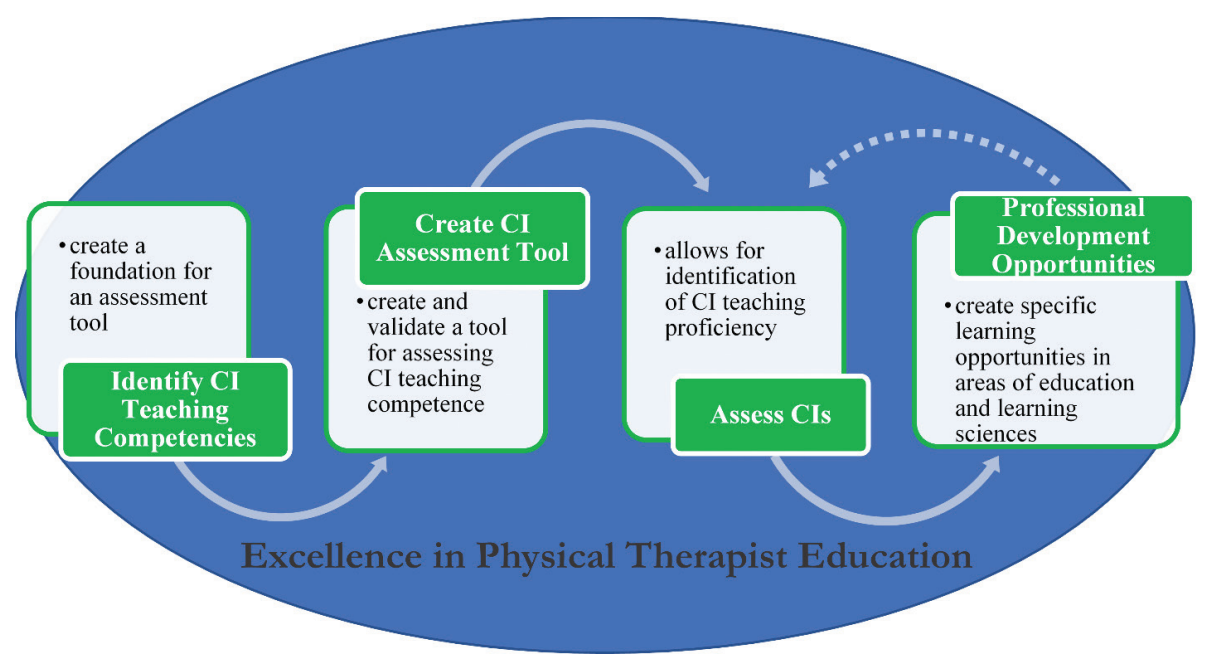

Fig. 1. Stepwise development of clinical instructor competencies and related assessment tool, housed within the framework of excellence in physical therapist education. 
profession, CIs may be driven to prioritize educational opportunities to advance their clinical teaching skills, rather than focusing only on skills related to clinical practice. As seen in medicine, faculty development programming should be increasingly focused on helping teachers acquire and enhance education delivery skills rather than leaving teachers to acquire competence in these skills through trial and error ${ }^{35}$ A systematic approach taken in the creation of professional development opportunities can lead to enhanced teaching skills, better job satisfaction, and better learner outcomes. ${ }^{29}$ Consistency and quality of clinical education experiences may then be enhanced by ensuring that the $\mathrm{CI}$ is empowered with the knowledge, skills, and attitudes necessary to provide an exceptional student learning experience. ${ }^{3,4}$

On the journey toward excellence in physical therapist education, all stakeholders must 'continually innovate and take risks to drive the shared vision for practice and education forward' (p. 119). ${ }^{16}$ The concept of excellence described in the National Study of Excellence and Innovation in Physical Therapist Education demands new levels of teaching confidence and expertise to develop adaptive learners who are primed to be excellent clinicians and future CIs. ${ }^{16}$ To advance the physical therapy profession, we must build upon the qualitative studies that have described desired clinical teaching behaviors and use examples from other professions to establish competencies for clinical educators. Only with objective, consensus-driven standards of competency can consistent, meaningful assessment and professional development opportunities arise. We can no longer settle for the status quo of minimum and inconsistent standards of clinical teaching - we must focus on a process to support each $\mathrm{CI}$ in the journey from novice educator across the continuum toward expert performance, contributing to a platform for excellence in the profession.

\section{Conflict of interest and funding}

The authors have no conflicts of interest and funding.

Preliminary work that led to this perspective paper was presented at the American Physical Therapy Association's 2020 Combined Sections Meeting in a session entitled 'Raising the Proverbial Bar: Development of a Novel Tool to Assess Clinical Educators'.

\section{Ethical approval}

Not applicable.

\section{References}

1. Jensen GM, Hack LM, Nordstrom T, et al. National study of excellence and innovation in physical therapist education: part 2-a call to reform. Phys Ther (2017) 97: 875-88. doi: 10.1093/ptj/ pzx062

2. Commision on Accreditation in Physical Therapy Education. Aggregate program data: 2018-2019 Physical therapist education programs fact sheet. Available from: http://www.capteonline.org/uploadedFiles/CAPTEorg/About_CAPTE/Resources/
Aggregate_Program_Data/AggregateProgramData_PTPrograms.pdf [cited 18 Mar 2020].

3. Recker-Hughes C, Wetherbee E, Buccieri KM, et al. Essential characteristics of quality clinical education experiences: standards to facilitate student learning. J Phys Ther Educ (2014) 28: 48-55. doi: 10.1097/00001416-201400001-00009

4. McCallum CA, Reed R, Bachman S, et al. A systematic review of physical therapist clinical instructor demographics and key characteristics: impact on student clinical education experiences. J Phys Ther Educ (2016) 30: 11-20. doi: 10.1097/00001416-201630030-00004

5. Mostrom E. What makes a good clinical teacher? In: Jensen GM, Mostrom E, eds. Handbook of teaching and learning for physical therapists, 3rd ed. St. Louis, MO: Elsevier/Butterworth-Heinemann; 2013, pp. 159-82.

6. Jensen GM, Nordstrom T, Mostrom E, et al. National study of excellence and innovation in physical therapist education: part 1-design, method, and results. Phys Ther (2017) 97: 857-74. doi: 10.1093/ptj/pzx061

7. Merriam SB, Bierema LL. Adult learning: linking theory and practice. 1 ed. San Francisco, CA: Jossey-Bass; 2014.

8. Coleman-Ferreira K, Tovin M, Rone-Adams S, et al. Achieving clinical instructor competence. J Phys Ther Educ (2019) 33: 224-35. doi: 10.1097/jte.0000000000000106

9. Recker-Hughes C, Brooks G, Mowder-Tinney JJ, et al. Clinical instructors' perspectives on professional development opportunities: availability, preferences, barriers, and supports. J Phys Ther Educ (2010) 24: 19-25. doi: 10.1097/00001416-201001000-00003

10. Buccieri KM, Pivko SE, Olzenak DL. How does a physical therapist acquire the skills of an expert clinical instructor? J Phys Ther Educ (2011) 25: 17-23. doi: 10.1097/00001416-201101000-00005

11. Housel N, Gandy J. Clinical instructor credentialing and its effect on student clinical performance outcomes. J Phys Ther Educ (2008) 22: 43-51. doi: 10.1097/00001416-200810000-00006

12. Morren KK, Gordon SP, Sawyer BA. The relationship between clinical instructor characteristics and student perceptions of clinical instructor effectiveness. J Phys Ther Educ (2008) 22: 52-63. doi: 10.1097/00001416-200810000-00007

13. Wetherbee E, Nordrum JT, Giles S. Effective teaching behaviors of apta-credentialed versus noncredentialed clinical instructors. J Phys Ther Educ (2008) 22: 65-74. doi: 10.1097/00001416-200801000-00010

14. American Physical Therapy Association. APTA learning center. Available from: https://learningcenter.apta.org/ [cited 3 January 2021].

15. Steinert Y, Mann K, Anderson B, et al. A systematic review of faculty development initiatives designed to enhance teaching effectiveness: a 10-year update. Med Teach (2016) 38: 769-86. doi: 10.1080/0142159X.2016.1181851

16. Jensen GM. Educating physical therapists. Thorofare, NJ: Slack Incorporated; 2019.

17. Buccieri KM, Pivko SE, Olzenak DL. Development of an expert clinical instructor: a theoretical model for clinical teaching in physical therapy. J Phys Ther Educ (2013) 27: 48-57. doi: 10.1097/00001416-201310000-00007

18. Jette DU, Nelson L, Palaima M, et al. How do we improve quality in clinical education? Examination of structures, processes, and outcomes. J Phys Ther Educ (2014) 28: 6-12. doi: 10.1097/00001416-201400001-00004

19. McCallum CA, Mosher PD, Jacobson PJ, et al. Quality in physical therapist clinical education: a systematic review. Phys Ther (2013) 93: 1298-311. doi: 10.2522/ptj.20120410 
20. Chen HC, Fogh S, Kobashi B, et al. An interview study of how clinical teachers develop skills to attend to different level learners. Med Teach (2016) 38: 578-84. doi: 10.3109/0142159X.2015.1073238

21. American Physical Therapy Association. Guidelines and self-assessments for clinical education. Available from: http://www. apta.org/Educators/Assessments/ACCE/DCE/GuidelinesandAssessmentsforClinEd/ [cited 1 March 2020].

22. American Physical Therapy Association. Physical therapist student evaluation: clinical experience and clinical instruction. Available from: http://www.apta.org/uploadedFiles/APTAorg/ Educators/Assessments/StudentPTEvaluationForm [cited 12 January 2020].

23. Wormley ME, Romney W, Schweizer K, et al. Using a valid and reliable measure to assess clinical instructor self-perception of teaching behaviors. J Phys Ther Educ (2018) 32: 344-54. doi: 10.1097/jte.000000000000006324

24. Gallivan SP. Construct validity and internal consistency of the physical therapist student evaluation of clinical experience and clinical instruction. University of Dayton OhioLINK Electronic Theses and Dissertations Center (2019). Available from: https://etd.ohiolink.edu/pg_10?0::NO:10:P10_ACCESSION_ NUM:dayton155497630642095 [cited 14 May 2020].

25. Galbraith RM, Hawkins RE, Holmboe ES. Making self-assessment more effective. J Contin Educ Health Prof (2008) 28: 20-4. doi: 10.1002/chp. 151

26. Verma S, Paterson M, Medves J. Core competencies for health care professionals: what medicine, nursing, occupational therapy, and physiotherapy share. J Allied Health (2006) 35: 109-15. doi: 10.3233/WOR-2012-1299

27. Batt AM, Tavares W, Williams B. The development of competency frameworks in healthcare professions: a scoping review. Adv Health Sci Educ Theory Pract (2020) 25: 913-87. doi: 10.1007/s10459-019-09946-w

28. Ramsburg L, Childress R. An initial investigation of the applicability of the Dreyfus skill acquisition model to the professional development of nurse educators. Nurs Educ Perspect (2012) 33: 312-6. doi: 10.5480/1536-5026-33.5.312

29. Srinivasan M, Li ST, Meyers FJ, et al. Teaching as a competency: competencies for medical educators. Acad Med (2011) 86: 1211-20. doi: 10.1097/ACM.0b013e31822c5b9a
30. Brink D, Simpson D, Crouse B, et al. Teaching competencies for community preceptors. Fam Med (2018) 50: 359-63. doi: 10.22454/FamMed.2018.578747

31. Promoting Teacher Effectiveness. Adult education teacher competencies. American Institues for Research. United States Department of Education. Available from: https://lincs.ed.gov/ state-resources/federal-initiatives/teacher-effectiveness/competencies [cited 19 January 2020].

32. Frank JR, Danoff D. The CanMEDS initiative: implementing an outcomes-based framework of physician competencies. Med Teach (2007) 29: 642-7. doi: 10.1080/01421590701746983

33. Kassis K, Wallihan R, Hurtubise L, et al. Milestone-based tool for learner evaluation of faculty clinical teaching. MedEdPORTAL (2017) 13: 10626. doi: 10.15766/ mep_2374-8265.10626

34. Nguyen VNB, Forbes H, Mohebbi M, et al. Development and validation of an instrument to measure nurse educator perceived confidence in clinical teaching. Nurs Health Sci (2017) 19: 498-508. doi: 10.1111/nhs. 12373

35. Rosenbaum M. Competencies in medical education. Soc Gen Intern Med Forum (2012) 35: 1-2.

36. American Physical Therapy Association. Education leadership partnership. Available from: https://www.apta.org/ELP/ [cited 20 January 2020].

37. Lyon LJ. Development of teaching expertise viewed through the dreyfus model of skill acquisition. J Schol Teach Learn (2015) 15: 88-105. doi: 10.14434/josotl.v15i1.12866

38. Ericcson K, Krampe R, Tesch-Romer C. The role of deliberate practice in the acquisition of expert performances. Psychol Rev (1993) 100: 363-406. doi: 10.1037/0033-295X.100.3.363

\section{*Catherine Bilyeu}

Physical Therapy Program

School of Medicine

University of Colorado

Mail Stop C244

13121 E. 17 th Avenue

Aurora, CO 80045

USA

Email: Catherine.Bilyeu@cuanschutz.edu 